\title{
ORTHOGONALLY ADDITIVE HOLOMORPHIC FUNCTIONS ON C*-ALGEBRAS
}

\author{
Antonio M. Peralta And Daniele Puglisi
}

Abstract. Let $A$ be a $\mathrm{C}^{*}$-algebra. We prove that a holomorphic function of bounded type $f$ : $A \rightarrow \mathbb{C}$ is orthogonally additive on $A_{s a}$ if, and only if, it is additive on elements having zeroproduct if, and only if, there exist a positive functional $\varphi$ in $A^{*}$, a sequence $\left(\psi_{n}\right)$ in $L_{1}\left(A^{* *}, \varphi\right)$ and a power series holomorphic function $h$ in $\mathscr{H}_{b}\left(A, A^{*}\right)$ such that

$$
h(a)=\sum_{k=1}^{\infty} \psi_{k} \cdot a^{k} \text { and } f(a)=\left\langle 1_{A^{* *}}, h(a)\right\rangle=\int h(a) d \varphi,
$$

for every $a$ in $A$, where $1_{A^{* *}}$ denotes the unit element in $A^{* *}$ and $L_{1}\left(A^{* *}, \varphi\right)$ is a noncommutative $L_{1}$-space.

Mathematics subject classification (2010): Primary 46G20, 46L05; Secondary 46L51, 46E15, 46E50. Keywords and phrases: $\mathrm{C}^{*}$-algebra, von Neumann algebra, orthogonally additive holomorphic functions, non-commutative $L_{1}$-spaces.

\section{REFERENCES}

[1] Y. Benyamini, S. Lassalle, And J. G. Llavona, Homogeneous orthogonally additive polynomials on Banach lattices, Bull. London Math. Soc. 38, 3 (2006), 459-469.

[2] M. Burgos, F. J. Fernández-Polo, J. J. Garcé, and A. M. Peralta, Orthogonality preservers Revisited, Asian-European Journal of Mathematics 2, 3 (2009), 387-405.

[3] D. CaRAndo, S. Lassalle, AND I. Zalduendo, Orthogonally additive polynomials over $C(K)$ are measures - a short proof, Integr. equ. oper. theory 56 (2006), 597-602.

[4] D. Carando, S. Lassalle, AND I. Zalduendo, Orthogonally Additive Holomorphic functions of Bounded Type over $C(K)$, Proc. of the Edinburgh Math. Soc. 53 (2010), 609-618.

[5] S. DineEn, Complex Analysis on infinite dimensional Spaces, Springer, 1999.

[6] J. A. Jaramillo, A. Prieto, I. Zalduendo, Orthogonally additive holomorphic functions on open subsets of $C(K)$, Rev. Mat. Complut. (2010), Pages 1-11. DOI: 10.1007/s13163-010-0055-2. Article in press.

[7] H. Kos AKI, Applications of the complex interpolation method to a von Neumann algebra: noncommutative $L^{p}$-spaces, J. Funct. Anal. 56, 1 (1984), 29-78.

[8] C. Palazuelos, A. M. Peralta, and I. Villanueva, Orthogonally Additive Polynomials on $C^{*}$-Algebras, Quart. J. Math. 59 (2008), 363-374.

[9] D. PÉREZ, AND I. VILlanUeVA, Orthogonally additive polynomials on spaces of continuous functions, J. Math. Anal. Appl. 306 (2005), 97-105.

[10] G. PISIER, Factorization of operators through $L_{p \infty}$ or $L_{p 1}$ and noncommutative generalizations, Math. Ann. 276, 1 (1986), 105-136.

[11] S. SAKAI, $C^{*}$-algebras and $W^{*}$-algebras, Springer-Verlag, Berlin, 1971.

[12] K. Sundaresan, Geometry of spaces of homogeneous polynomials on Banach lattices, Ap plied geometry and discrete mathematics, 571-586, DIMACS Ser. Discrete Math. Theoret. Comput. Sci., 4, Amer. Math. Soc., Prov., RI, 1991.

[13] M. TAKESAKI, Theory of operator algebras, I, Springer-Verlag, New York-Heidelberg, 1979. 